\title{
Punching Behavior Of Self-Compacting Concrete Slabs Incorporating Coarse Recycled Concrete Aggregates
}

\author{
Malik K. E. Altaee ${ }^{1}$ | Jamal A. S. Khudair ${ }^{1}$
}

\section{Affiliations}

${ }^{1}$ Civil Eng. Department, College of engineering, University of Basrah, Iraq

\section{Correspondence}

Malik K. E. Altaee,

Civil Eng. Department, College of

Engineering, University of Basrah, Iraq

Email: mailkaltaee@hotmail.com

\section{Received}

23-January-2020

Revised

29-February-2020

Accepted

03-March-2020

doi: $10.31185 /$ ejuow.Vol8.Iss1.147

\begin{abstract}
This paper presents an experimental investigation on the effects of incorporating coarse recycled concrete aggregates (RCA) on the punching and flexural behaviour of reinforced concrete two-way slabs. For this purpose, four concrete mixes were designed with various substitution ratios of natural coarse aggregates (NCA) by RCA $0 \%$ (reference mix), 25, 50 and $75 \%$. Subsequently, fourteen $800 \times 800 \mathrm{~mm} \times$ variable thickness reinforced concrete slabs (two per concrete type) were cast and subjected to punching and flexural tests. Different parameters that affect the behavior of two-way slabs were studied including type of failure, replacement ratios of NCA by RCA, amount of main reinforcement, thickness and loading patch size. In order to investigate the effect of RCA incorporation on hardened concrete properties (compressive strength $\mathrm{Fcu}$, tensile $\mathrm{Ft}$ strength, flexural Fr strength and modulus of elasticity Ec), different replacement ratios were considered, while the quantity of cement was kept equaled for all the mixes (with and without RCA). Hardened concrete samples results showed that Fcu, Ft, Fr and Ec were decreased by $(8.62,13.54$ and $19.12 \%),(13.08,17.63$ and $25.46 \%),(10.02,21.67 \%$, and $34.30 \%)$ and $(9.69,15.65$ and $16.62 \%)$ respectively, for the $(25,50$ and $75 \%)$ replacement ratios compared with samples made from SCC without RCA. The experimental results of slabs showed that the cracking and ultimate load $(11 \%$ maximum reduction ratio) and moment (19.5\% maximum reduction ratio) capacities of slabs were decreased compared with slabs made from SCC without RCA. Moreover, the load deflection curves were almost identical with proportional increase to the RCA content. From the general behavior, ultimate capacity, deflections, failure angle and crack pattern results, it can be concluded that the recycled concrete aggregate can be used as a partial replacement of natural coarse aggregate to produce self-compacting concrete mixes, where the behavior of two-way slabs cast with SCC containing RCA can considered acceptable.
\end{abstract}

\footnotetext{
Keywords: Concrete slabs, punching shear, structural behavior, self-compacted concrete, recycled coarse aggregate.

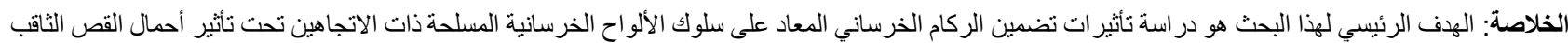

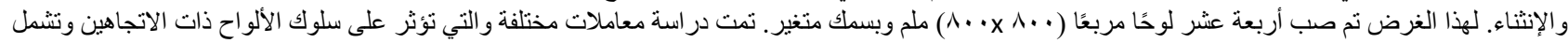

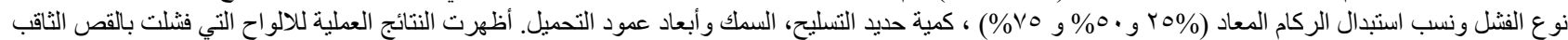

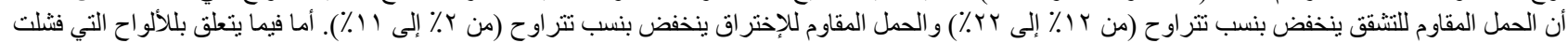

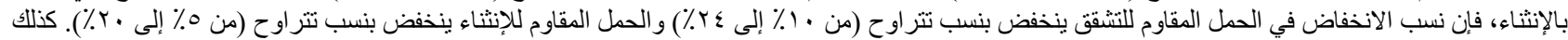

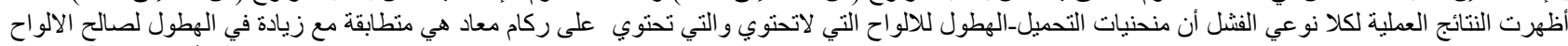

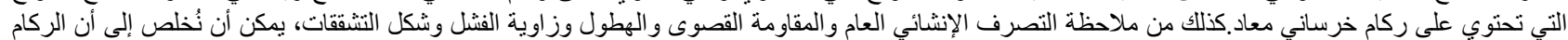

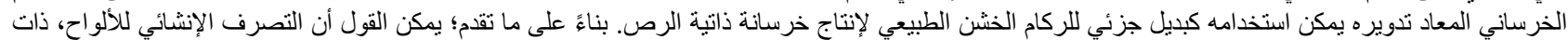

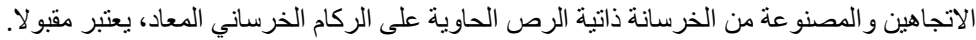




\section{INTRODUCTION}

The construction industry and concrete manufacturers have realized that they will need to use available aggregate materials rather than search for the perfect aggregate to make an ideal conc rete suitable for all purposes. Simultaneously, important increases in concrete recycling result in millions of tons of Recycled Concrete Aggregate (RCA) that could be used in the production of concrete for particular purposes. Here in Iraq, the amount of demolition wastes is undisputed due to subsequent wars at this country. Unfortunately, neither record for amount of demolition wastes nor a waste management are available. Making use of this recycled materials based on sufficient financial plans can lead to a very positive impact on environment, human health and safety.

Currently, RCA is mainly being used as an alternate material for natural aggregate in unlimited sub-base and base pavement layers in road construction. Until today the research of RCA is mostly carried out in countries such as United States, Europe and Japan, while in other countries this research still in its initial stages. Many countries are using this RCA mostly for the non-structural elements because the research is limited to basic physical and mechanical properties. Due to the low strength, low elastic modulus, bad workability, high water absorption, high shrinkage and creep of RCA, it is mostly used for only non-structural concrete. However, for greater applications, it is necessary to investigate the feasibility of producing different RCA structural elements with locally available waste concrete.

Sadati et al. [1], performed a study to investigate the bond strength between concrete and reinforcing steel in full-scale beams constructed with various "green" concrete mixtures, including high- concrete containing $50 \%$ Class $\mathrm{C}$ fly ash as cement replacement (FA50), concrete with 50\% of coarse RCA replacement (RCA50), as well as (SC) proportioned with $50 \%$ Class C fly ash and 50\% RCA. Performance of SC mixture was similar to that of RCA50 $(50 \%$ of coarse RCA replacement), which were both slightly $(6 \%)$ lower than that of the FA50 (50\% Class C fly ash replacement) beams in terms of bond strength. Ozbakkaloglu et al. [2], presented a study on the mechanical and durability properties of concretes manufactured with recycled aggregates of different sizes and contents. Their results showed that for a given $\mathrm{w} / \mathrm{c}$ ratio, the compressive strength of RAC decreased with an increase in the recycled aggregate replacement ratio. The flexural and the splitting tensile strengths of both NSC and HSC mixes were also decreased with an increase in RCA\%. Reis et al. [3], conducted experimental, numerical and analytical investigations about the effects of incorporating coarse recycled concrete aggregates (CRCA) on the punching behaviour of reinforced concrete two-way slabs. Four concrete mixes with replacement ratios of $0,20,50$ and $100 \%$ were used. They concluded that the incorporation of CRCA affects the mechanical behaviour of RC slabs where the stiffness decreased, particularly in the uncracked state and the cracking load slightly decreased.

Francesconi et al. [4], reported the experimental assessment of the punching shear behaviour of reinforced recycled concrete two-way slabs characterized by fine natural aggregates and coarse recycled aggregates. Four replacement percentages $(30,50,80$ and $100 \%)$ of coarse recycled aggregates in place of coarse natural aggregates have been considered. Their results showed that the reduced recycled concrete performance does not translate directly to the punching shear strength of slabs. Also, they mentioned that in all slabs, punching shear failure was detected regardless of the presence of recycled aggregates. Showjendra and Reddy [5], studied the influence of recycled aggregate on the structural behavior of two-way slabs under punching shear and flexural loading. Six concrete mix proportions were used with $0,20,40,60,80$ and $100 \%$ replacement of natural coarse aggregate with recycled coarse aggregate. Some of the slabs were simply supported and other restrained. Their conclusions showed that the first cracking load, ultimate failure load and stiffness decreased as the replacement of natural coarse aggregate concrete with recycled coarse aggregate concrete increased. They also concluded that replacement of natural coarse aggregate with recycled coarse aggregate up to $40 \%$ is quite suitable and the resulting recycled aggregate concrete slabs present similar behavior when compared with the natural coarse aggregate concrete slabs in terms of the punching shear and flexural properties. Mahmoud et al. [6], presented an experimental study on punching shear behavior of simply supported natural and recycled coarse aggregate concrete two-way slabs. They used four concrete mix proportions with $(0 \%, 30 \%, 60 \%$ and $100 \%)$ replacement of natural coarse aggregate with recycled coarse aggregate for each aggregate size. The test results showed that the first punch crack load, ultimate punch load, stiffness and energy absorption decreased as the replacement of natural coarse aggregate with recycled coarse aggregate increased. Moreover, as the recycled aggregate size increased the cracking and failure load increased.

The above literature review shows that the researches on punching behavior of concrete slabs with partial RCA are limited. Most of these research dealt with normal concrete. In this study, self-compacting concrete slabs with partial replacement of RCA were prepared and tested for flexure and punching shear. 


\section{EXPERIMENTAL PROGRAM}

\subsection{Materials}

Ordinary Portland cement and natural fine aggregate (sand) were used. Natural coarse aggregate was used with different replacement ratios of RCA. Both of them having same gradation zone and satisfying (Iraqi specification No.45/1984) [7] requirements. The recycled aggregate was prepared by manually crushing concrete cubes belong to ongoing project in Basra. The crushed concrete was divided into two sizes (10 to 14 and 5 to $10 \mathrm{~mm}$ ) by utilizing sieves, these two fractions were mixed in proportions to obtain grading comparable to that of natural aggregate, Table 1 and Table 2. Tap water from the water-supply network was added. The high range water reducer (HRWR), Glenium 51, was used to get self-compacting concrete (SCC). Limestone powder locally named AL-Gubra was bought from local market and used as a filler material in the production of SCC. Ukrainian brand deformed steel reinforcing bars with different diameters (Ø8mm, Ø10mm and Ø12mm) were used which satisfy the (ASTM A615/ A615M-05) [8].

Table 1. Grading of NCA and RCA.

\begin{tabular}{|c|c|c|c|}
\hline \multirow{2}{*}{$\begin{array}{c}\text { Sieve size } \\
\text { mm }\end{array}$} & \multicolumn{3}{|c|}{ Passing (\%) by weight } \\
\cline { 2 - 4 } & NCA & RCA & Limits of IOS No.45/1984 \\
\hline 20 & 100 & 100 & $100-95$ \\
\hline 14 & 82 & - & - \\
\hline 10 & 37 & 35 & $30-60$ \\
\hline 5 & 2 & 0 & $0-10$ \\
\hline
\end{tabular}

Table 2. Physical properties of NCA and RCA.

\begin{tabular}{|l|c|c|c|}
\hline \multicolumn{1}{|c|}{ Physical properties } & $\begin{array}{c}\text { Natural Coarse } \\
\text { Aggregate }\end{array}$ & $\begin{array}{c}\text { Recycled Coarse } \\
\text { Aggregate }\end{array}$ & $\begin{array}{c}\text { Limits of IOS } \\
\text { No.45/1984 }\end{array}$ \\
\hline Specific gravity & 2.65 & 1.65 & - \\
\hline Sulfate content $\left(\mathrm{SO}_{3}\right)$ & 0.073 & - & $\leq 0.1 \%$ \\
\hline Chloride content $(\mathrm{Cl})$ & 0.092 & - & $\leq 0.1 \%$ \\
\hline Absorption & 0.65 & 3.91 & - \\
\hline Loose bulk density kg/m ${ }^{3}$ & 1500 & 960 & - \\
\hline
\end{tabular}

\subsection{Concrete mixes}

Four types of SCC mixes were used. Mix one was made with natural coarse aggregate ( $0 \%$ RCA) and the remaining three mixes were containing RCA as a partial replacement of NCA at replacement ratios of (25\%, 50\% and $75 \%)$. In all SCC mixes, RCA ratios were left to have their impact on concrete properties at 28-day age with a tolerance of \pm (1.5 to 2) $\mathrm{MPa}$ against average value. Many trial mixes where prepared in order to meet fresh SCC requirements for mixes made with natural and with recycled concrete aggregates, the quantity of cement was the same for all mixes $(0 \%, 25 \%, 50 \%$ and $75 \%$ ) as shown in Table 3.

Table 3. Mix design proportion ratios.

\begin{tabular}{|l|c|}
\hline \multicolumn{1}{|c|}{ Material } & Content \\
\hline Cement $\mathrm{kg} / \mathrm{m}^{3}$ & 403 \\
\hline $\begin{array}{l}\text { Limestone Powder } \\
\mathrm{kg} / \mathrm{m}^{3}\end{array}$ & 172 \\
\hline Coarse Aggregate & 840 \\
\hline Fine Aggregate $\mathrm{kg} / \mathrm{m}^{3}$ & 803 \\
\hline Water $\mathrm{kg} / \mathrm{m}^{3}$ & 178 \\
\hline Glenium $51 \mathrm{~kg} / \mathrm{m}^{3}$ & 4 \\
\hline
\end{tabular}




\subsection{Mixing Procedure}

Rotary drum mixer was employed, prior to commence mixing, the mixer has been cleaned and moistened from inside. Mixing procedure, developed by (Jin J.) [9] was adopted throughout this research. Figure 1 shows the mixing procedure used along this study.

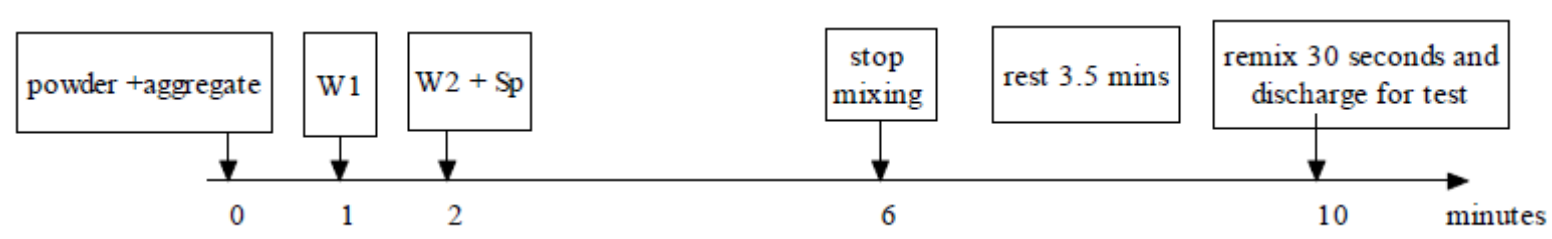

$\mathrm{W} 1=80 \%$ mixing water

$\mathrm{W} 2=20 \%$ mixing water

Sp: superplasticizer

Figure 1 Concrete mixing procedure, (Jin J.) [9].

1. Powder (cement and limestone) and aggregate were mixed for one minute;

2. The water first part (W1) (80\%) of mixing water was added slowly while mixing and then mixed for further one minute;

3. The water second part (20\%) of mixing water plus superplasticizer, mixed together, was added slowly while mixing for 4 minutes;

4. Rest for 3.5 minutes;

5. Remixing for 30 seconds for the mix to be ready.

\subsection{Slabs Details}

Fourteen slabs, with and without RCA, designed to fail in punching shear (G1 and G2) and flexure (G3). Square slabs were cast with dimensions $800 \times 800 \mathrm{~mm}$ and variable thicknesses. The slabs were cast with different reinforcement ratios and three mixes were considered depending on RCA replacement percentages. Table 4 and Figure 2 present slabs details.

Table 4. Details of slabs.

\begin{tabular}{|c|c|c|c|c|c|c|c|}
\hline G & Slabs & $\begin{array}{c}\text { Steel } \\
\text { Amount }\end{array}$ & RCA \% & $\begin{array}{c}\text { Col Dim. } \\
\text { mm }\end{array}$ & $\begin{array}{l}\text { Thk } \\
\text { mm }\end{array}$ & Din & sion \\
\hline \multirow{6}{*}{ G1 } & $2 W 50 \%$ & \multirow{6}{*}{ 9Ф12 } & $0 \%$ & $150 \times 150$ & 100 & 80 & 80 \\
\hline & $2 W 850 \%$ & & $50 \%$ & $150 \times 150$ & 100 & 80 & 80 \\
\hline & $2 W 60 \%$ & & $0 \%$ & $100 \times 100$ & 100 & 80 & 80 \\
\hline & $2 W 950 \%$ & & $50 \%$ & $100 \times 100$ & 100 & 80 & 80 \\
\hline & $2 W 180 \%$ & & $0 \%$ & $200 \times 200$ & 100 & 80 & 80 \\
\hline & $2 W 20$ & & $50 \%$ & $200 \times 200$ & 100 & 80 & 80 \\
\hline \multirow{4}{*}{ G2 } & $2 W 70 \%$ & \multirow{2}{*}{$17 \Phi 12$} & $0 \%$ & $150 \times 150$ & 150 & 80 & 80 \\
\hline & $2 W 10$ & & $50 \%$ & $150 \times 150$ & 150 & 80 & 80 \\
\hline & $2 W 110 \%$ & \multirow{2}{*}{$17 \Phi 10$} & $0 \%$ & $150 \times 150$ & 150 & 80 & 80 \\
\hline & $2 W 12$ & & $50 \%$ & $150 \times 150$ & 150 & 80 & 80 \\
\hline \multirow{4}{*}{ G3 } & $2 W 10 \%$ & \multirow{4}{*}{$9 \Phi 8$} & $0 \%$ & $150 \times 150$ & 120 & 80 & 80 \\
\hline & $2 W 225 \%$ & & $25 \%$ & $150 \times 150$ & 120 & 80 & 80 \\
\hline & $2 W 350 \%$ & & $50 \%$ & $150 \times 150$ & 120 & 80 & 80 \\
\hline & $2 W 475 \%$ & & $75 \%$ & $150 \times 150$ & 120 & 80 & 80 \\
\hline
\end{tabular}




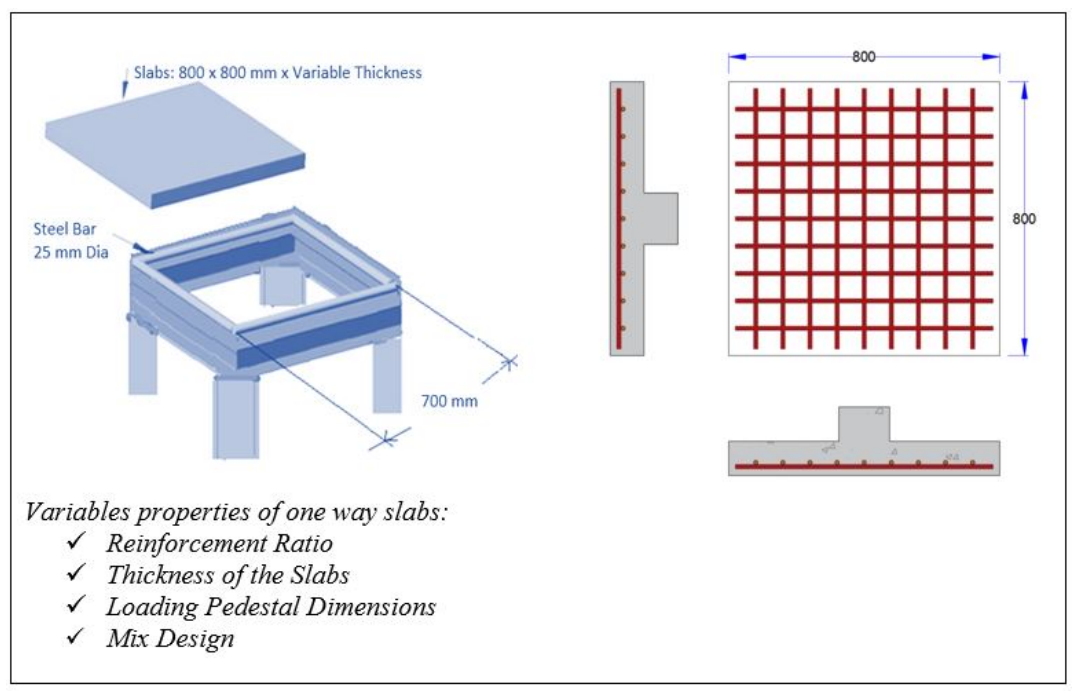

Figure 2 Slabs Details.

\subsection{Casting, Curing and Testing of Slabs}

Slabs details and properties as per section 3.4. The steel reinforcement grids were fabricated and placed in their exact locations in the epoxy-painted plywood shutters, all molds were prepared for casting by oiling along the interior surfaces of the mold in order to prevent adhesion with concrete after hardening. No vibrator was used during concreting. Concrete was poured in one place inside the shutters and left to spread by its property of self-compacting, the surfacing done by using a steel trowel for the purpose of well finishing, the concrete finished to the same level of the shutter walls. Three cubes, three flexural prisms and six cylinders were cast for each concreting day, to evaluate the compressive strength, modulus of elasticity, splitting tensile strength. The slabs, cubes and cylinders were covered with wet canvas and polyethylene sheet for three weeks. All the slabs formworks were removed after three weeks from casting date. Before starting tests, the slabs were white painted, by using water solved paint, from bottom and both long sides for the cracks to be clear visible at earliest cracking loads. The locations, where the loads applied and the supports, where highlighted Electronic dial gauges of $0.01 \mathrm{~mm} / \mathrm{div}$ was used for deflection measurement at mid-span.

\section{EXPERIMENTAL WORK RESULTS}

\subsection{Fresh and Hardened Properties of SCC with or without RCA}

The fresh and hardened properties of SCC are shown in Table 5 and Table 6 respectively. For fresh concrete three types of tests were conducted to satisfy SCC requirements. These tests include slump-flow, V-Funnel and L-Box test. These tests were done based on (EFNARC-2005) [10] requirements.

It is known that the consistency of normal concrete and SCC is adversely affected by adding recycled concrete aggregates [11-2]. The results of this study (Table 5) explicitly support this fact. The slump flow is shown to be decrease continuously with the increase of RCA replacement ratio. Similarly, the T500 time and V-funnel time increased with the increase of RCA replacement ratio.

For hardened concrete, the compressive strength, tensile strength, modulus of elasticity and modulus of rapture were determined.

Table 2. Tests results of fresh self-compacting concrete.

\begin{tabular}{|c|c|c|c|c|c|c|c|c|c|c|c|c|}
\hline \multirow{2}{*}{$\begin{array}{l}\text { RCA } \\
(\%)\end{array}$} & \multirow{2}{*}{$\begin{array}{c}\text { Slump } \\
\text { flow } \\
(\mathbf{m m})\end{array}$} & \multicolumn{2}{|c|}{$\begin{array}{l}\text { EFNARC } \\
\text { Guideline }\end{array}$} & \multirow{2}{*}{$\begin{array}{l}\text { T } 500 \\
\text { (sec) }\end{array}$} & \multicolumn{2}{|c|}{$\begin{array}{l}\text { EFNARC } \\
\text { Guideline }\end{array}$} & \multirow{2}{*}{$\begin{array}{c}\text { V- } \\
\text { funnel } \\
\text { (sec) }\end{array}$} & \multicolumn{2}{|c|}{$\begin{array}{l}\text { EFNARC } \\
\text { Guideline }\end{array}$} & \multirow{2}{*}{$\begin{array}{c}\text { L- } \\
\text { Box }\end{array}$} & \multicolumn{2}{|c|}{$\begin{array}{l}\text { EFNARC } \\
\text { Guideline }\end{array}$} \\
\hline & & Min. & Max & & Min & Max & & Min & Max & & Min & Max \\
\hline 0 & 710 & 650 & 800 & 2.76 & 2 & 5 & 8.47 & 8 & 12 & 0.96 & 0.8 & 1.00 \\
\hline 25 & 700 & 650 & 800 & 2.79 & 2 & 5 & 8.55 & 8 & 12 & 0.92 & 0.8 & 1.00 \\
\hline 50 & 690 & 650 & 800 & 2.90 & 2 & 5 & 8.86 & 8 & 12 & 0.89 & 0.8 & 1.00 \\
\hline 75 & 640 & 650 & 800 & 3.40 & 2 & 5 & 9.81 & 8 & 12 & 0.89 & 0.8 & 1.00 \\
\hline
\end{tabular}

Table 3. Properties of hardened self-compacted concrete.

\begin{tabular}{|c|c|c|c|c|c|}
\hline SN & RCA $\%$ & $\mathbf{F}_{\mathbf{c u}} \mathbf{M P a}$ & $\mathbf{F}_{\mathbf{t}} \mathbf{M P a}$ & $\mathbf{F}_{\mathbf{r}} \mathbf{M P a}$ & $\mathbf{E}_{\mathbf{c}} \mathbf{G P a}$ \\
\hline 1 & $0 \%$ & 42.1 & 3.822 & 5.86 & 27.67 \\
\hline 2 & $25 \%$ & 38.47 & 3.322 & 5.80 & 24.99 \\
\hline 3 & $50 \%$ & 36.40 & 3.148 & 4.59 & 23.34 \\
\hline 4 & $75 \%$ & 34.05 & 2.849 & 3.85 & 23.07 \\
\hline
\end{tabular}


As the RCA replacement increases the compressive strength, tensile strength (splitting and flexural test) and modulus of elasticity decrease. This result is in agreement with the vast available literature on recycled aggregate concrete [13-15]. This relation can be represented in exponential relationship between control value (zero replacement), replacement ratios of RCA and value at any replacement ratios from $0 \%$ to $75 \%$. Figure 3 represents the relation between RCA replacement, compressive strength (Fcu), tensile strength and modulus of elasticity.
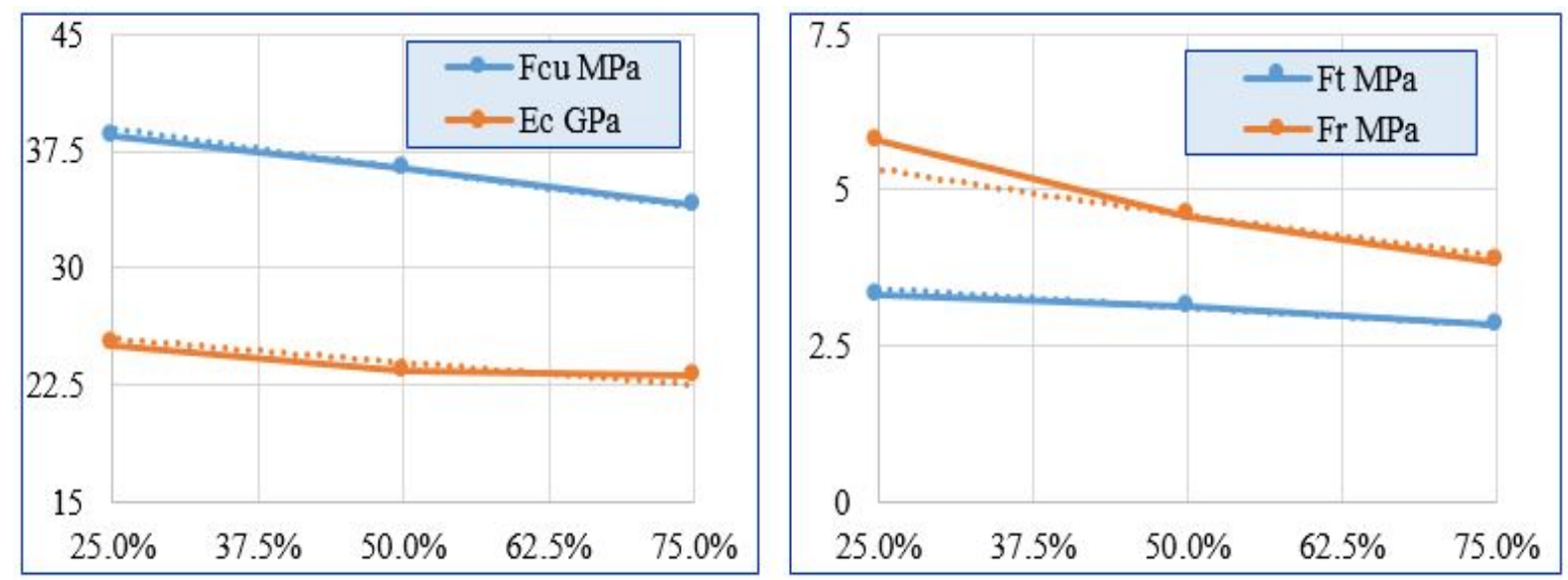

Figure 2 Relation between RCA replacement, compressive strength ( Fcu), tensile strength and modulus of elasticity.

\subsection{Results and Discussion}

\subsubsection{Hardened Concrete Properties}

It can be seen from Table 7 that when the compressive strength of the RCA concrete is lower than that of the conventional concrete, the tensile strength (for both flexural and splitting tests) of the RCA concrete decreases gradually with the increase of RCA replacement ratios, and the decrease rate increase significantly with the increase of the strength difference between the conventional concrete and the RCA concrete. The decrease ratios of the modulus of elasticity, due to RCA replacements are generally close to that for compressive strengths.

Table 4. Decrease in hardened concrete properties due to RCA content.

\begin{tabular}{|c|c|c|c|c|c|}
\hline $\mathbf{S N}$ & $\mathbf{R C A} \%$ & $\mathbf{F}_{\mathbf{c u}} \mathbf{M P a}$ & $\mathbf{F}_{\mathbf{t}} \mathbf{M P a}$ & $\mathbf{F}_{\mathbf{r}} \mathbf{M P a}$ & $\mathbf{E}_{\mathbf{c}} \mathbf{G P a}$ \\
\hline 2 & $25 \%$ & $8.62 \%$ & $13.08 \%$ & $10.10 \%$ & $9.69 \%$ \\
\hline 3 & $50 \%$ & $13.54 \%$ & $17.63 \%$ & $21.67 \%$ & $15.65 \%$ \\
\hline 4 & $75 \%$ & $19.12 \%$ & $25.46 \%$ & $34.30 \%$ & $16.62 \%$ \\
\hline
\end{tabular}

\subsubsection{Structural Behavior}

Test results are presented in Table 8 and Table 9. The effect of different parameters such as replacement ratios of RCA, longitudinal reinforcement, slab thickness and loading patch size on the cracking, ultimate capacities and type of failure is demonstrated below:

Table 5. Shows the cracking and ultimate loads of Slabs failed in punching shear (G1 and G2).

\begin{tabular}{|c|c|c|c|c|c|c|c|c|c|c|c|}
\hline $\mathbf{G}$ & Slabs & $\begin{array}{c}\text { Steel } \\
\text { Amount }\end{array}$ & $\begin{array}{c}\text { RCA } \\
\% \\
\end{array}$ & $\begin{array}{c}\text { Col Dim. } \\
\text { mm }\end{array}$ & $\begin{array}{c}\text { Thick. } \\
\text { mm }\end{array}$ & Dim & $\mathbf{m m}$ & $P_{c r} \mathbf{k N}$ & $\begin{array}{c}P_{u} \\
(k N)\end{array}$ & $\mathbf{P}_{\mathrm{cr}} / \mathbf{P}_{\mathrm{u}}$ & $\begin{array}{l}\text { Type of } \\
\text { Failure } \\
\end{array}$ \\
\hline \multirow{6}{*}{ G1 } & 2W6 0\% & \multirow{6}{*}{$9 \Phi 12$} & $0 \%$ & $100 \times 100$ & 100 & 800 & 800 & 45 & 160 & 0.28 & P. Shear \\
\hline & 2W9 50\% & & $50 \%$ & $100 \times 100$ & 100 & 800 & 800 & 35 & 145 & 0.24 & P. Shear \\
\hline & 2W5 0\% & & $0 \%$ & $150 \times 150$ & 100 & 800 & 800 & 57 & 200 & 0.29 & P. Shear \\
\hline & $2 \mathrm{~W} 850 \%$ & & $50 \%$ & $150 \times 150$ & 100 & 800 & 800 & 50 & 192.5 & 0.26 & P. Shear \\
\hline & $2 \mathrm{~W} 180 \%$ & & $0 \%$ & $200 \times 200$ & 100 & 800 & 800 & 73 & 275 & 0.26 & P. Shear \\
\hline & $2 \mathrm{~W} 2050 \%$ & & $50 \%$ & $200 \times 200$ & 100 & 800 & 800 & 62 & 270 & 0.23 & P. Shear \\
\hline \multirow{4}{*}{ G2 } & 2W7 0\% & \multirow{2}{*}{$17 \Phi 12$} & $0 \%$ & $150 \times 150$ & 150 & 800 & 800 & 110 & 405 & 0.27 & P. Shear \\
\hline & $2 \mathrm{~W} 1050 \%$ & & $50 \%$ & $150 \times 150$ & 150 & 800 & 800 & 95 & 360 & 0.26 & P. Shear \\
\hline & $2 \mathrm{~W} 110 \%$ & \multirow{2}{*}{$17 \Phi 10$} & $0 \%$ & $150 \times 150$ & 150 & 800 & 800 & 105 & 360 & 0.29 & P. Shear \\
\hline & $2 \mathrm{~W} 1250 \%$ & & $50 \%$ & $150 \times 150$ & 150 & 800 & 800 & 92.5 & 335 & 0.28 & P. Shear \\
\hline
\end{tabular}


Table 6. Shows the cracking and ultimate moments of slabs failed in flexure (G3).

\begin{tabular}{|c|c|c|c|c|c|c|c|c|c|c|c|}
\hline $\mathbf{G}$ & Slabs & $\begin{array}{l}\text { Steel } \\
\text { Amnt. }\end{array}$ & $\begin{array}{c}\text { RCA } \\
\%\end{array}$ & $\begin{array}{c}\text { Col Dim. } \\
\text { mm }\end{array}$ & $\begin{array}{l}\text { Thick. } \\
\text { mm }\end{array}$ & Dim & mm & $\begin{array}{c}M_{\text {cr }} \\
\text { kN.m }\end{array}$ & $\begin{array}{c}M_{u} \\
\text { kN.m }\end{array}$ & $\begin{array}{l}\mathbf{M}_{\mathrm{cr}} / \\
\mathbf{M}_{\mathbf{u}}\end{array}$ & $\begin{array}{l}\text { Type of } \\
\text { Failure }\end{array}$ \\
\hline \multirow{4}{*}{ G3 } & $2 \mathrm{~W} 10 \%$ & \multirow{4}{*}{$9 \Phi 8$} & $0 \%$ & $150 \times 150$ & 120 & 800 & 800 & 7.36 & 20.82 & 0.35 & Flexure \\
\hline & $2 \mathrm{~W} 225 \%$ & & $25 \%$ & $150 \times 150$ & 120 & 800 & 800 & 6.60 & 19.80 & 0.33 & Flexure \\
\hline & $2 \mathrm{~W} 350 \%$ & & $50 \%$ & $150 \times 150$ & 120 & 800 & 800 & 6.06 & 18.28 & 0.33 & Flexure \\
\hline & $2 W 475 \%$ & & $75 \%$ & $150 \times 150$ & 120 & 800 & 800 & 5.59 & 16.76 & 0.33 & Flexure \\
\hline
\end{tabular}

\subsubsection{Cracking and Ultimate Loads of Slabs failed in Punching Shear}

As shown in Table 8, the cracking load and ultimate load were decreased with the increase in the replacement ratio. The decrease in ultimate load ascribed to the reduction in concrete strength accompanying to the increase in RCA replacement ratio, consequently, concrete crushing in the compression zone would take place at smaller loads for those slabs. Whereas the decrease in cracking load was due higher strain and the low strength of concrete in tension fibers produced in slabs of RCA ratios.

The slabs were classified into two groups based on pedestal size and reinforcement amount. The effect of the different parameters affecting the behavior of slabs in groups G1 and G2 is discussed below.

\section{- $\quad$ 1 (Slabs $2 W 5 \& 2 W 8,2 W 6,2 W 9,2 W 18$ and $2 W 20)$}

\section{Replacement ratio:}

These slabs have identical reinforcement ratios and thicknesses. When RCA replacement percentage increase from $0 \%$ to $50 \%$, the cracking load and ultimate load were decreased by $22 \%$ and $9 \%$, respectively ( $2 \mathrm{~W} 9$ vs $2 \mathrm{~W} 6), 13 \%$ and $4 \%$, respectively ( $2 \mathrm{~W} 8$ vs $2 \mathrm{~W} 5$ ), and $14 \%$ and $2 \%$, respectively ( $2 \mathrm{~W} 20$ vs $2 \mathrm{~W} 18)$.

\section{Pedestal Dimensions:}

The less pedestal size (2W6 0\% and 2W9 50\%), has the most apparent impact of replacing NCA by RCA. That, the RCA concrete lose $10 \%$ of its ultimate strength when the loaded area is $2 \%$ of the clear area of the slab.

Increasing the pedestal size from $(100 \times 100) \mathrm{mm}$ to $(150 \times 150) \mathrm{mm}$ and $(200 \mathrm{x} \mathrm{200}) \mathrm{mm}(2 \mathrm{~W} 60 \%$ - Reference Slab), $(2 \mathrm{~W} 50 \%$ ) and (2W18 0\%) respectively, increase the ultimate load $(\mathrm{Pu})$ by $25 \%$ and $72 \%$, respectively. In same manner, but for RCA slabs, increasing the pedestal size from [100mm x $100 \mathrm{~mm}$ ] to [150mm x $150 \mathrm{~mm}$ ] and [200mm x 200mm] for (2W9 50\%- Reference Slab), (2W8 50\%) and (2W20 50\%) respectively, increase the ultimate load (Pu) by $33 \%$ and $69 \%$, respectively. Thus, both NCA and RCA slabs have a consistent response to the changing pedestal dimension except for RCA slabs (2W8 50\% / 2W9 50\%) where the pedestal dimension increased from (100mm x $100 \mathrm{~mm})$ to $(150 \mathrm{~mm} \mathrm{x}$ $150 \mathrm{~mm})$ produced $32 \%$ increment above the increment of $25 \%$ of $(2 \mathrm{~W} 50 \%$ / $2 \mathrm{~W} 60 \%)$.

\section{- $\quad$ 2 2 (Slabs $2 W 70 \% 2 W 1050 \% 2 W 110 \% 2 W 1250 \%)$}

\section{Reinforcement amount:}

This group is devoted to illustrate the effect of reinforcement amount and slab thickness on the behavior of slabs. When RCA replacement percentage increase from $0 \%$ to $50 \%$, the cracking load and ultimate load were decreased by $14 \%$ and $11 \%$ respectively ( $2 \mathrm{~W} 10$ vs $2 \mathrm{~W} 7$ ) and $12 \%$ to $7 \%$ respectively ( $2 \mathrm{~W} 12$ vs $2 \mathrm{~W} 11)$.

From the results of G2, by comparing $2 \mathrm{~W} 70 \%$ to $2 \mathrm{~W} 110 \%$, these two slabs differ from each other in reinforcement amount only. When the reinforcement amount decreased from that of $2 \mathrm{~W} 70 \%$ to that of $1 \mathrm{~W} 110 \%$, the ultimate punching load decreased by $11 \%$. In the same way of comparison, when the reinforcement amount decreased from that of $2 \mathrm{~W} 10$ $50 \%$ to that of $1 \mathrm{~W} 1250 \%$, the ultimate punching load decreased by $7 \%$. So it can be observed that the effect of changing reinforcement ratio become less where RCA is used, this variance belonged to that the concrete with RCA transform less stresses to the embedded steel, i.e. the bond stress become less when RCA is being used as literally reviewed in Section 2.

\section{Thickness:}

Slabs 2W5 0\% \& 2W8 50\% of G1, these slabs have a thickness of $100 \mathrm{~mm}$ and pedestal dimension of $150 \mathrm{~mm} \mathrm{x}$ $150 \mathrm{~mm}$, showed an ultimate load decrement ratio of $4 \%$. On the other hand, slabs $2 \mathrm{~W} 110 \%$ \& $2 \mathrm{~W} 1250 \%$ of G2, these slabs have a thickness of $150 \mathrm{~mm}$ and pedestal dimension of $150 \mathrm{~mm} \times 150 \mathrm{~mm}$, showed an ultimate load decrement ratio of $7 \%$. So, by considering the effect of different reinforcement amount between the slabs, it can be observed that changing the slabs thickness does not have that a significant effect on using RCA concrete. 


\subsubsection{Size of the Failure Zone and Failure Angles (Punching Slabs - G1 and G2)}

The failure angle that creates punching pyramid is measured from the edge of the pedestal (loaded area) to the center line of the reinforcement grid as shown in Figure 6.

Failure patterns are shown in Figure 4. Table 10 presents the size and inclination angle of the punching pyramid of shear failure of the slabs. All the slabs have been failed in an identical behavior, sudden failure with limited warning was noticed in both types, concrete with and without RCA. the failure shape was ranged between nearly circle and elliptical shape and its size was decreasing as the RCA involved in.

The surface of punching shear cone on the tension face occurred at a distance $(X)$ from the pedestal edge. This distance (X) ranges between 1.4 to 2.22 times the effective depth (d) in the slabs without RCA replacement and ranges between 1.32 to 2.13 in the slabs with RCA replacement.

From Table 10, it can be observed that the surface failure (cone surface) angle increases for slabs with RCA replacement. This increase due to decrease in concrete compression strength, as when Fc decreases the size of the failure zone decrease and that when size of the failure zone decreases angle of the failure will increase $(\theta=d / X)$ where $X$ refers to failure surface size and $d$ is a constant).

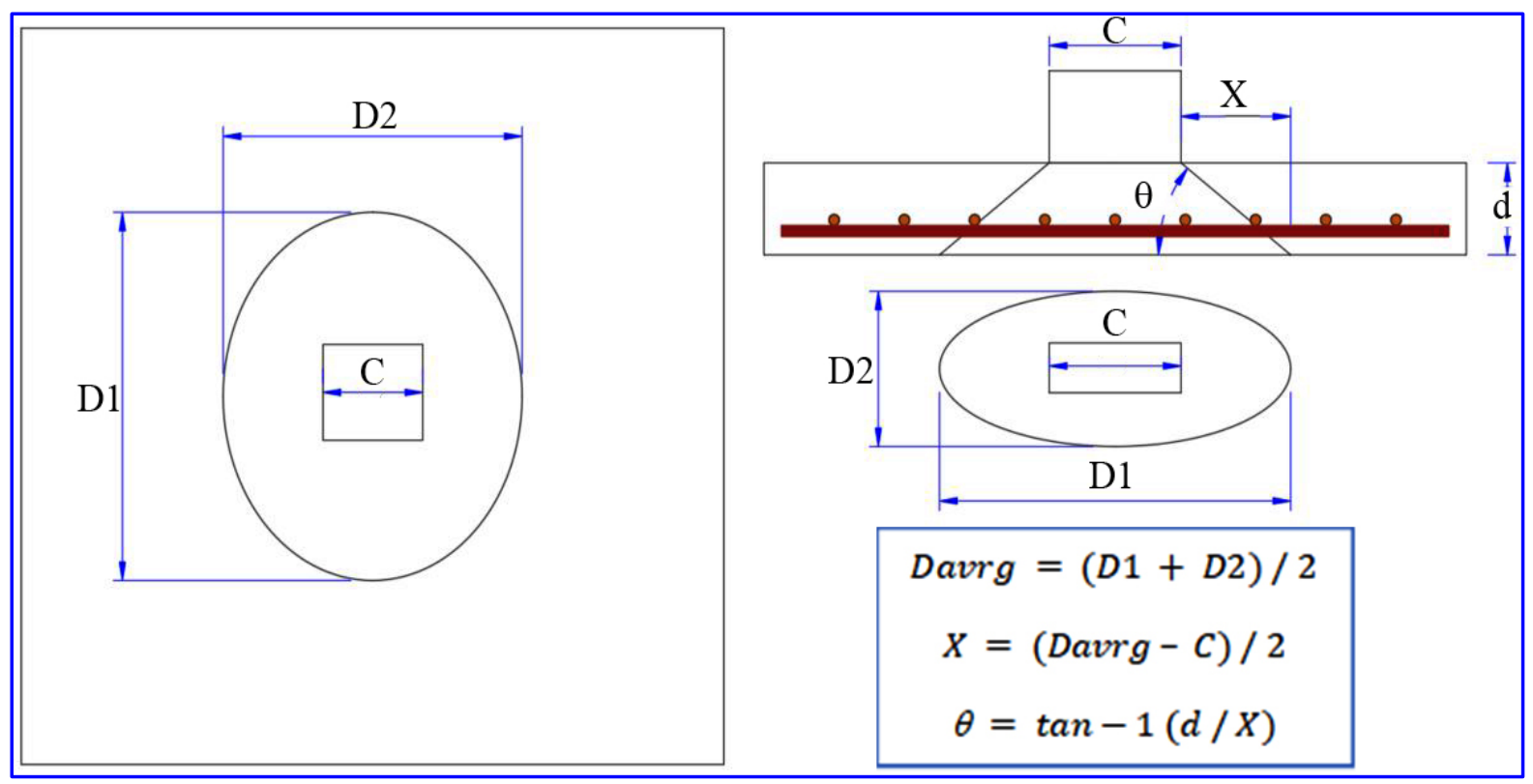

Figure 3 Size and angle of failure zone.

Table 7. Size and angle of failure zone.

\begin{tabular}{|c|c|c|c|c|c|c|c|c|c|}
\hline \multirow{2}{*}{ SN } & \multirow{2}{*}{ Slabs } & \multirow{2}{*}{$\begin{array}{c}\text { Steel } \\
\text { Amount }\end{array}$} & \multirow{2}{*}{ RCA \% } & \multicolumn{2}{|c|}{ Punching Size } & \multirow{2}{*}{ d mm } & \multirow{2}{*}{$\mathrm{X} \mathbf{~ m m}$} & \multirow{2}{*}{$d / X$} & \multirow{2}{*}{$\theta^{\circ}$} \\
\hline & & & & D1 mm & D2 mm & & & & \\
\hline \multirow{6}{*}{ G1 } & 2W5 $0 \%$ & \multirow{6}{*}{$9 \Phi 12$} & $0 \%$ & 466.7 & 445.5 & 74 & 153.03 & 0.484 & 25.8 \\
\hline & $2 \mathrm{~W} 850 \%$ & & $50 \%$ & 460.8 & 427.9 & 74 & 147.18 & 0.503 & 26.8 \\
\hline & $2 \mathrm{~W} 60 \%$ & & $0 \%$ & 429 & 429 & 74 & 164.52 & 0.450 & 24.2 \\
\hline & 2W9 50\% & & $50 \%$ & 420 & 411.8 & 74 & 157.94 & 0.469 & 25.1 \\
\hline & 2W18 0\% & & $0 \%$ & 500 & 460 & 74 & 140.00 & 0.529 & 27.9 \\
\hline & $2 \mathrm{~W} 2050 \%$ & & $50 \%$ & 460 & 460 & 74 & 130.00 & 0.569 & 29.6 \\
\hline \multirow{4}{*}{ G2 } & $2 \mathrm{~W} 70 \%$ & \multirow{2}{*}{$17 \Phi 12$} & $0 \%$ & 530 & 520 & 124 & 187.50 & 0.661 & 33.5 \\
\hline & $2 \mathrm{~W} 1050 \%$ & & $50 \%$ & 490 & 480 & 124 & 167.00 & 0.740 & 36.5 \\
\hline & $2 \mathrm{~W} 110 \%$ & \multirow{2}{*}{$17 \Phi 10$} & $0 \%$ & 520 & 480 & 125 & 175.00 & 0.714 & 35.5 \\
\hline & $2 \mathrm{~W} 1250 \%$ & & $50 \%$ & 480 & 480 & 125 & 165.00 & 0.758 & 27.1 \\
\hline
\end{tabular}

\subsubsection{Cracking and Ultimate Moments of Slabs failed in Flexure}

\section{- Group G $3(2 W 10 \% 2 W 225 \% 2 W 350 \% 2 W 475 \%)$}

When RCA replacement ratios increase from $0 \%$ to $25 \%$, the cracking moment decreased by $10.34 \%$ and ultimate moment decreased by 5\%, further increase in RCA replacement percentage to $50 \%$, the cracking moment decreased by $17.7 \%$ and ultimate moment decreased by $12.2 \%$ and when RCA percentage read $75 \%$, the cracking moment and ultimate moment reduced by $24 \%$ and $19.5 \%$ respectively. 


\subsubsection{Load - Deflection Curves of Slabs}

The load versus deflection curves for SCC reinforced concrete slabs with and without RCA are needed as a part of description of structural behavior of slabs. One electronic dial gauge was used with a maximum capacity equal to $50 \mathrm{~mm}$ to measure the deflection at the center of the bottom face of slabs, Figure 5.

It can be noticed that the slabs with RCA replacement experience higher deflections than those of zero replacement. The increase in the deflections for slabs with RCA replacement pertaining to the lower modulus of elasticity of recycled concrete aggregate.

A change in the slope of the curves occurred after the formation of flexural cracks, because the formation of the first major crack significantly reduced slab stiffness, therefore the deflection was increased at a higher rate (slope decrease).
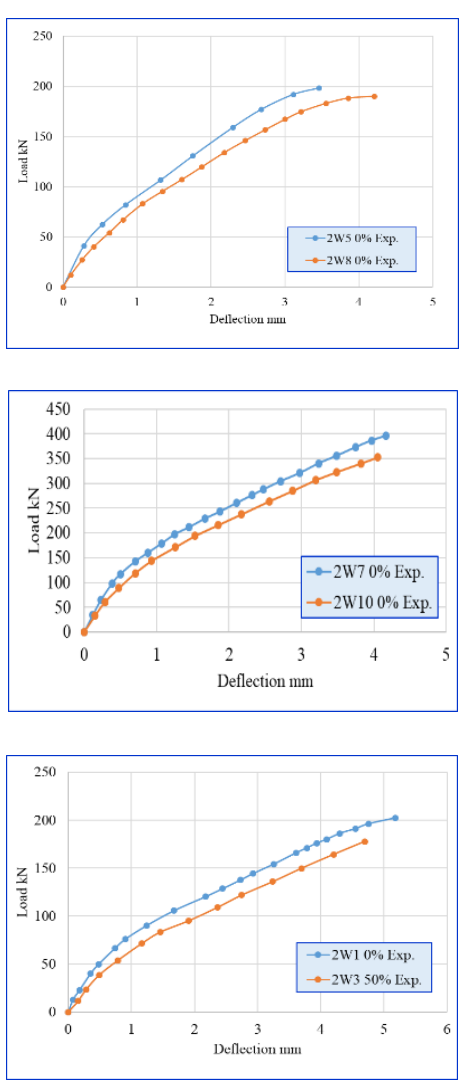
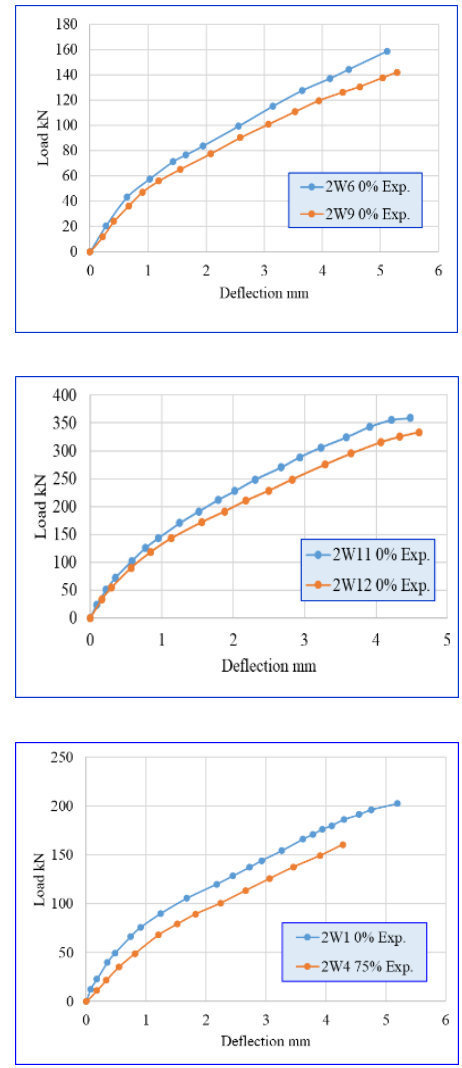
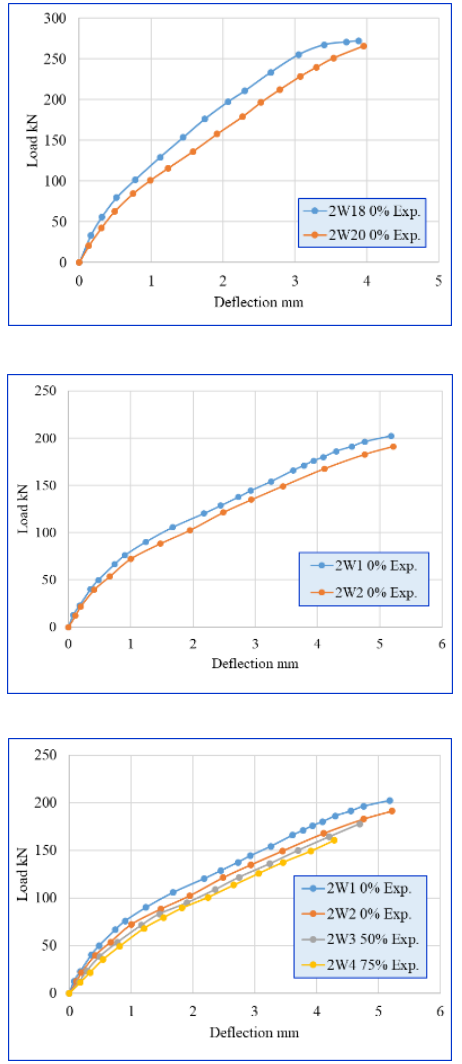

Figure 4 Experimental load versus mid-span deflection curve Slabs.

\subsubsection{Crack Pattern and Mode of Failure}

\subsection{Two-Way Slab Failed in Punching (G1 and G2)}

Figure 6 shows the crack patterns and mode of failure for these slabs. The major cracks have been highlighted to make them clear and other very fine cracks left without highlighting. Crack pattern and failure behavior of slabs, with and without RCA were almost identical. First visible crack appeared at the tension face of slabs at a load level of $(23 \%$ to $29 \%$ ) of the ultimate load. Cracks at early loading levels in the tensile zone were acted upon semi-random phenomena. At higher loads, the formed cracks became wider and new cracks were formed. These new cracks were shaped like a semi-circular and elliptical in the tension zone of the slabs. Failure of the slabs happened when the pyramid failure radiates outward from the point of load application pushed down through the slab body, brittle and with limited failure warning. At failure, the slab reinforcement, through visual inspection, was capable of taking additional load as it is not yet reached yield point. 


\subsubsection{Two-Way Slab Failed in Flexure (G3)}

In general, all slabs failed under bending. Flexural cracks started at the center of the slab, first cracks began at (33\% to $35 \%$ ) of the ultimate flexural load, that apparently using RCA replacement effect and weaken the slab from the first stage of loading, Table 9 shows the first cracks loads for all slabs.

Flexural cracks started at the center of the slab, under increasing load, these cracks developed diagonally towards the four support corners, symmetrically located across the entire tension face as illustrated in Figure 7. As failure load was reached, the deflection was increased and cracks were propagated rapidly.
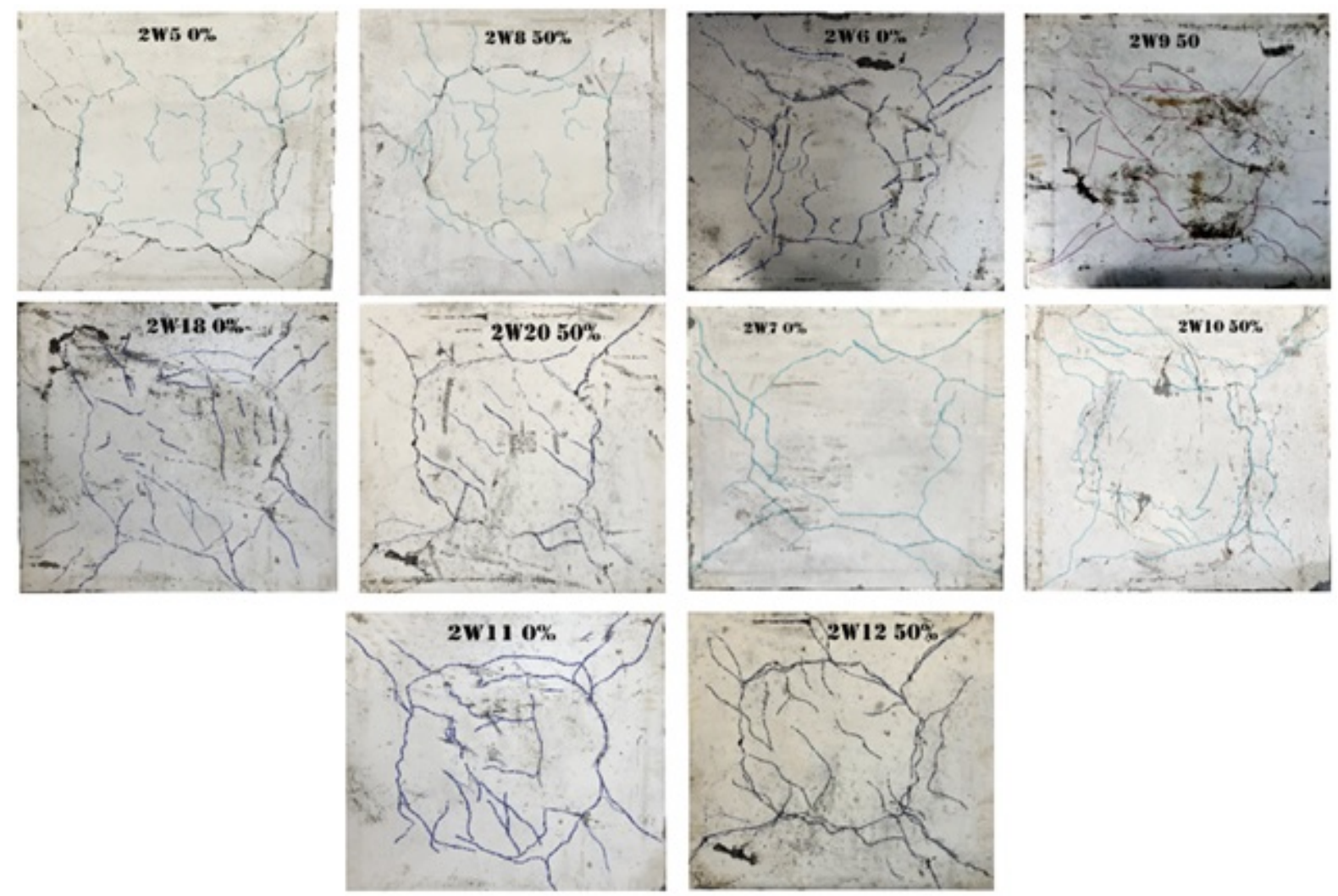

Figure 5 Cracks pattern of slabs failed in punching shear.
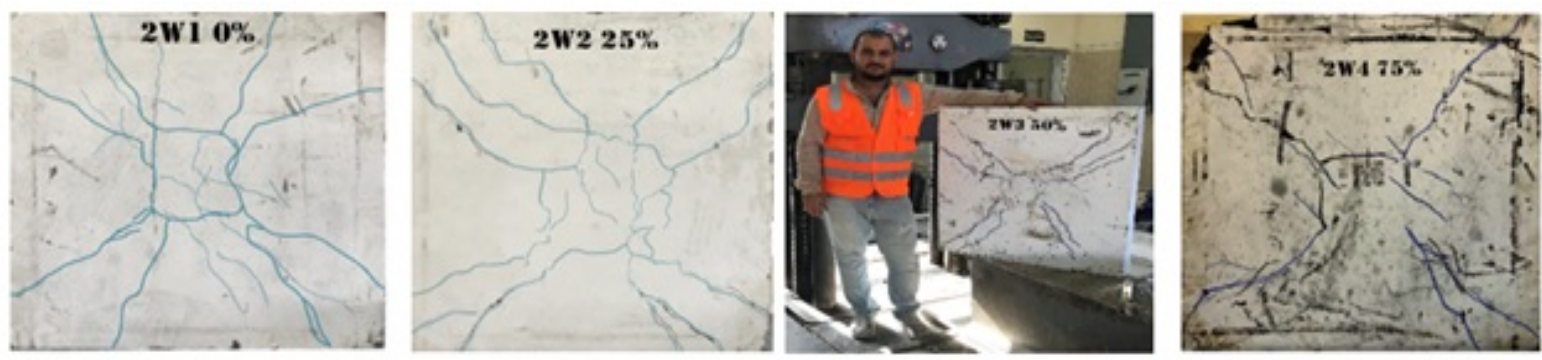

Figure 6 Cracks pattern of slabs failed in flexure.

\section{CONCLUSIONS}

Based on the experimental results carried out, the below can be concluded:

- From Slump Flow, V-Funnel and L-Box tests, the flowability, filling ability and passing ability of self-compacted concrete decreased as RCA replacement increased.

- Fcu, Ft, Fr and E values decreased as the RCA replacement increased.

- Including of RCA in concrete mixes make the first crack appear earlier (for both punching and flexure slabs) in comparison to slabs made of NCA concrete. 
- The cracking and ultimate load capacity of slabs failed in punching shear decreased when RCA is added to the mixes. The maximum decrease ratio was for slabs $2 \mathrm{~W} 1050 \%$, where the cracking and ultimate loads decreased by $14 \%$ and $11 \%$ respectively.

- The cracking and ultimate moment capacity of slabs failed in flexure decreased when RCA is added to the mixes. The maximum decrease ratio was for slabs $2 \mathrm{~W} 475 \%$ where the cracking moment and ultimate moment decreased by $24 \%$ and $19.5 \%$ respectively.

- both NCA and RCA slabs have a consistent response to the changing pedestal.

- The effect of increasing reinforcement amount become less by using RCA.

- Changing slabs thickness does not have that apparent effect on using RCA concrete in slabs fabrication.

- Slabs containing RCA induce higher deflection. The maximum increase ratio was for slabs $2 \mathrm{~W} 475 \%$ where the ultimate deflection increased by $18.9 \%$ at the same load level of $2 \mathrm{~W} 10 \%$.

- The surface failure (cone surface) angle increases for slabs with RCA replacement, these increases differ for each pair of punching slabs.

- For both concrete types (with and without RCA), the general behavior of the cracks is almost same except the cracks of slabs with RCA replacement is greater in quantity and slightly wider.

- A significant consideration to be given to that fact that these conclusions build on specific size slabs.

\section{REFERENCES}

1. Sadati S, Arezoumandi M, Khayat H, \& Volz S. (2017). Bond performance of sustainable reinforced concrete beams. ACI Mat J, 114(4), 537-547.

2. Ozbakkaloglu T, Gholampour A, \& Xie T, (2018). Mechanical and durability properties of recycled aggregate concrete: effect of recycled aggregate properties and content. Journal of Materials in Civil Engineering, 30(2), 04017275 .

3. Reis N, de Brito J, Correia R, \& Arruda R, (2015). Punching behaviour of concrete slabs incorporating coarse recycled concrete aggregates. Engineering structures, 100, 238-248.

4. Francesconi L, Pani L, \& Stochino F, (2016). Punching shear strength of reinforced recycled concrete slabs. Construction and Building Materials, 127, 248-263.

5. Reddy, V. S. K. (2012). Behaviour of recycled aggregate concrete two way slabs in flexure and punching shear an experimental investigation.

6. Mahmoud I and Saeed J,(2018). Punching shear behavior of recycled aggregate reinforced concrete slabs. 57(2): p. 841-849.

7. IQS No. 45/1984, "Aggregate from Natural Sources for Concrete" Central Agency for Standardization and Quality Control, Planning Council, Baghdad Iraq, translated from Arabic edition.

8. ASTM, S.J.A.A.A.M.-b., Standard specification for deformed and plain carbon-steel bars for concrete reinforcement. 2009.

9. Jin J,(2002).Properties of Mortar for Self-Compacting Concrete" Ph.D. Thesis, Department of Civil and Environmental Engineering, University College London, University of London, 398pp.

10. Concrete, S. C. (2005). The European Guidelines for Self-Compacting Concrete. BIBM, et al, 22.

11. Silva, R. V., De Brito, J., \& Dhir, R. K. (2018). Fresh-state performance of recycled aggregate concrete: A review. Construction and Building Materials, 178, 19-31.

12. Santos, S., P. Da Silva, and J.J.J.o.B.E. De Brito, (2019). Self-compacting concrete with recycled aggregates-a literature review. 22: p. 349-371.

13. Cabral, A. E. B., Schalch, V., Dal Molin, D. C. C., \& Ribeiro, J. L. D. (2010). Mechanical properties modeling of recycled aggregate concrete. Construction and Building Materials, 24(4), 421-430.

14. De Brito, J., Ferreira, J., Pacheco, J., Soares, D., \& Guerreiro, M. (2016). Structural, material, mechanical and durability properties and behaviour of recycled aggregates concrete. Journal of Building Engineering, 6, 1-16.

15. Verian, K. P., Ashraf, W., \& Cao, Y. (2018). Properties of recycled concrete aggregate and their influence in new concrete production. Resources, Conservation and Recycling, 133, 30-49.. 